\section{Intervention analysis of introduction of rotavirus vaccine on hospital admissions rates due to acute diarrhea}

\author{
Análise de intervenção da introdução da vacina do \\ rotavirus nas taxas de internação hospitalar por \\ diarreia aguda
}

\author{
Análisis de intervención en la introducción de \\ la vacuna contra el rotavirus en las tasas de \\ hospitalización por diarrea aguda
}

\author{
Maria de Lourdes Teixeira Masukawa ${ }^{1}$ \\ Adriana Mayumi Moriwaki 1 \\ Nelson Shozo Uchimura 2 \\ Eniuce Menezes de Souza 3 \\ Taqueco Teruya Uchimura ${ }^{3}$
}

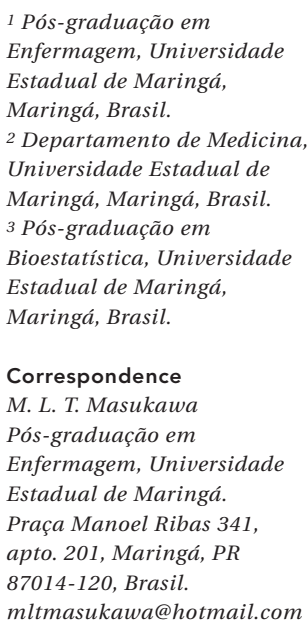

1 Pós-graduação em Enfermagem, Universidade Estadual de Maringá, Maringá, Brasil.

2 Departamento de Medicina

Universidade Estadual de Maringá, Maringá, Brasil.

3 Pós-graduação em

Bioestatística, Universidade

Estadual de Maringá,

Maringá, Brasil.

Correspondence

M. L. T. Masukawa Pós-graduação em Enfermagem, Universidade Estadual de Maringá. Praça Manoel Ribas 341, apto. 201, Maringá, PR 87014-120, Brasil.

mltmasukawa@hotmail.com

\begin{abstract}
The aim of this study is to investigate the impact of rotavirus vaccine on hospitalization rates for acute diarrhea in children younger than 5 years old after the introduction of the vaccine in 2006. A descriptive analytical observational study was carried out of the hospitalization rates occurred between 2000 and 2011 in 22 Regional Health Centers of Paraná State, Brazil. The effect of the vaccine was assessed by applying the SARIMA/Box-Jenkins time series methodology of intervention analysis, which allows verifying the slopes of the series are different after the introduction of the vaccine and estimating the magnitude of these effects for children younger than five years of age, by age group, for each region center. It was verified a statistically significant reduction by center/month on hospitalization rates for children 1 year old and younger, with averages of $47 \%$ and $58 \%$, respectively, in December 2011.
\end{abstract}

Rotavirus Vaccine; Diarrhea; Hospitalization; Health Services Evaluation

\section{Resumo}

O objetivo desse estudo é investigar o impacto da vacina do rotavírus nas taxas de internação por diarreia aguda em crianças menores de cinco anos após a introdução da vacina em 2006. Foi realizado um estudo analítico observacional descritivo das taxas de hospitalização ocorridas entre 2000 e 2011, em 22 Centros Regionais de Saúde do Estado do Paraná, Brasil. O efeito da vacina foi avaliado por séries temporais aplicando a metodologia SARIMA/Box-Jenkins com análise da intervenção, a qual permite verificar que os declives das séries são diferentes após a introdução da vacina, bem como estimar a magnitude desses efeitos para crianças menores de cinco anos de idade, por faixa etária, para cada região. Verificou-se redução estatisticamente significativa por centro/mês nas taxas de internação por diarreia aguda para as crianças menores de 1 ano de idade e de 1 ano de idade, com médias de $47 \%$ e 58\%, respectivamente, em dezembro de 2011.

Vacinas contra Rotavirus; Diarreia; Hospitalização; Avaliação de Serviços de Saúde 


\section{Introduction}

Diarrhea is the second leading cause of death among children under 5 years old in the world, affecting approximately 1.5 million children per year. Currently, $39 \%$ of children with diarrhea in developing countries receive the recommended treatment, and limited data until now suggests some progress since 20001.

Worldwide, rotavirus is considered one of the most important agents of gastroenteritis and death in children under 5 years old. It is estimated that every year there are 125 million diarrhea cases associated with rotavirus, resulting in 418,000 to 520,000 deaths, $85 \%$ of which are in less-developed regions. These data reflect $20 \%$ of global mortality by diarrheal disease and $5 \%$ of the total of deaths of children younger than 5 years old 2 .

In Brazil, the oral vaccine of human rotavirus (VORH) was included in National Program of Immunization (PNI) in March 2006, resulting in less severe intestinal diseases in children less than 5 years of age; we observed effects on infant mortality ${ }^{3}$. According to the Brazilian Ministry of Health, the diarrhea incidence associated with rotavirus varies between $12 \%$ and $42 \%$ based on estimates that approximately 2,500 children younger than 5 years old died per year before the introduction of the vaccine.

Clinical tests of VORH demonstrated that for the first year of life, there was an effective protection of $87.1 \%$ against any gastroenteritis caused by rotavirus, of $95.8 \%$ against acute gastroenteritis caused by rotavirus, and of $91.8 \%$ against gastroenteritis caused by rotavirus demanding medical assistance; finally, VORH prevented $100 \%$ of hospitalizations due to gastroenteritis by rotavirus 4,5 . These studies detected a $29 \%$ reduction in hospitalizations due to acute diarrhea in children younger than 1 year old, making necessary vaccination coverage equal or higher than $95 \%{ }^{2}$.

After the introduction of VORH in many countries, the reduction in hospitalization rates (HRs) was verified as it was in Brazil. Published studies indicating the reduction of HRs due to acute diarrhea in Brazil noticed a decline for children until 24 months, with a $48 \%$ reduction for the year 2007 when compared with the pre-vaccination period 6 . However, for Southern regions, there was no significant decline in HRs. Other evaluations, with a longer period of use of the VORH through 20097 for children younger than 2 years old, presented reductions of $21 \%$ in $2007,11 \%$ in 2008 , and $24 \%$ in 2009 . However, for Southern regions, the HRs declined by $12 \%$ in $2007,11 \%$ in 2009 , and increased by $27 \%$ in 2008 . The southern region has 3 heterogeneous states, and analysis of all 3 together may account for the obtained results. Thus, the aim of the present study is to verify the effect of the VORH on HRs due to acute diarrhea in children younger than 5 years old by using official data of Health Informatics Department (DATASUS) in Paraná State in Southern Brazil between 2000 and 2011. Analyzing data from each one of the 22 regional health divisions of Paraná State, which decreases the geographic analysis units, makes them more homogeneous 8 .

With regards to the methodology, Lanziere et al. ${ }^{6}$ used descriptive analysis and Carmo et al. ${ }^{7}$ applied regression methods. No studies were found of the vaccine effect using specific methods for time series modeling. In this sense, this paper examines the effect of the VORH on HRs due to acute diarrhea using a time series investigation with analysis of intervention by Box-Jenkins methodology.

Intervention time series (ITS) analysis models the effect of an external and known intervention on data such as counts of events collected regularly in time. Such data or time series often show serial dependence in which observations are correlated with previous ones (one or more months, in the case of seasonal effects). Appropriate methods for handling such data enable some interventions to be modeled and their effect can be estimated after adjusting for serial dependence, trends, and seasonal effects, by using linear models to quantify increases or decreases in the mean level or slope of the series. ITS analysis tests the causal hypothesis that the mean level or slope of the time-series is different after the intervention, or seeks to estimate the magnitude of intervention effects.

ITS is typically conducted with the Box \& Jenkins Auto-regressive Integrated Moving Average ARIMA (http://stats.stackexchange.com/tags/ arima/info) framework, using the methods outlined by Box \& Tiao 10. However, other methods such as segmented regression may be used. These 2 time series methods, adequately applied, enable the effect of the event to be separated from general trends and serial dependencies in time, thereby enabling valid statistical inferences to be made about whether an intervention has had an effect on a time series. Ramsay et al. 11 emphasized the necessity of correct modeling and analysis of interrupted time series. The paper showed that many ITS studies in the literature had analytical shortfalls. Thus, these considerations justify the importance of the application of this methodology, which is briefly described in the next section.

\section{Methodology}

Descriptive-analytical observational study of monthly hospitalization rates due to acute diar- 
rhea in children younger than 5 years old was performed between 2000 and 2011 in Paraná State. The research was performed with data from Paraná State, located in Southern Brazil, with an area of $199,880,202 \mathrm{~km}^{2}$. The state has a humid subtropical climate in the Northeast, coastal plains, and a subtropical climate in the South. In 2011, the population of Paraná State was 10,512,349 of which $718,805(6.84 \%)$ were younger than 5 years old. The State is administratively divided into $399 \mathrm{mu}$ nicipalities that are grouped in 22 regional health divisions (Instituto Brasileiro de Geografia e Estatística. Censo Demográfico de 2000. http:/ / www. ibge.gov.br).

The study population was composed of all children younger than 5 years old living in Paraná State who were hospitalized by Brazilian Unified National Health System (SUS) due to acute diarrheal diseases between January 2000 and December 2011.

The available data in the electronic address of the DATASUS (www.datasus.gov.br) were obtained from the System of Hospital Information of SUS (SIH-SUS) by using the 10th revision of the International Classification of Diseases (CID-10) with the codes A00 and A09.

The age groups included younger than 1 year old (until 11 months and 29 days), 1 year old (older than or equal to 12 months to 23 months and 29 days), 2 years old (older than or equal to 24 months to 35 months and 29 days), 3 years old (older than or equal to 36 months to 47 months and 29 days) and 4 years old (older than or equal to 48 months to 59 months and 29 days). The calculation of the HR due to acute diarrhea was performed by dividing the number of hospitalizations due to acute diarrhea by the population of each age group and multiplying the coefficient per 10,000. The values of the population used in the rate calculus from 1 to 4 years old groups were the Brazilian Institute of Geography and Statistics (IBGE) census in the years 2000 and 2010; the inter census estimates were used from IBGE for the remaining years. For the age group younger than 1 year old, the values of the population were obtained from Information System on Live Births (SINASC).

The data were processed in Tabwin program (DATASUS. http://portal.saude.gov.br/portal/ se/datasus/area.cfm?id_area=732), Excel (Microsoft Corp., USA), and R program (The R Foundation for Statistical Computing, Vienna, Austria; http://www.r-project.org). In R program, the packages t-series, and TSA (Times Series Analyses) were used to implement the methodology.

First, a descriptive analysis was performed for each age group and the monthly HR time series were analyzed for the 22 regional health divisions of Paraná State.
For the time series modeling with ITS analysis, the identification, estimation, and validation of the models considering the Box \& Jenkins Seasonal ARIMA (SARIMA) methodology was applied for all HR time series. The choice of SARIMA models is due to the fact some series present seasonal characteristics. The general model for a time series $Y_{t}$ is given by

$Y_{t}=N_{t}+m_{t}$

where $N_{t}$ represents the time series before the intervention modeled by a SARIMA process 10,11 $m_{t}$ and is the change in the mean function due to the intervention. Before the intervention, $m_{t}$ is assumed to be zero. To specify $m_{t}$, a function such as a pulse or step is useful 9. Pulse interventions refer to temporary effects (only a limited number of time periods), whereas step interventions lead to a permanent change in the time series, which is the case under study. Both functions can be represented by a binary or dummy variable, and in the case of a pulse intervention, it takes the value of 1 only for the time period when the intervention occurs. In the case of a step intervention, it takes a value of 1 starting in the time period when the intervention occurs as well as in all time periods thereafter.

The increases or decreases in the slope of the time series after the event can be estimated from the data by applying transfer functions 11 to this step function. These transfer functions modify simple step or pulse functions to represent a range of possible effects or changes that may occur after a period of intervention. Thus, the estimated parameter of most interest is the slope post-intervention. Furthermore, the effect of the intervention on time series can be projected for the actual time by multiplying the slope by the number of observations during the period post-intervention.

In relation to $N_{t}$ in equation (1), before identification of the best-fitting model $N_{t}$, the time series must be transformed, if necessary, into one that is stationary, which means that the mean and the auto-covariance do not depend on time. Roughly speaking, the mean and the variance are constant in the time series period. The stationarity can be induced through first or second differencing, or through a Box-Cox transformation 12. There are several ways to check for non-stationarity, including plotting the data to inspect visually for shifts in the series, observing a slow decay of the autocorrelation (ACF), or performing the Dickey-Fuller test for stationarity.

When the time series shows stable behavior over the entire period of the study (outside of the period due to the intervention), SARIMA models can be fit directly to the data series or to a series that has been treated to induce stationarity 12 . To 
identify the best-fitting SARIMA models considering the serial dependences, the ACF and partial auto-correlation function (PACF) for the stationary series are compared with the ACF and PACF of theoretical models 12,13 ,

In the estimation step, the data are used to estimate the parameters of the chosen model for $N_{t}$, by the maximum likelihood method. Once the parameters are estimated, the validity of the estimated model is checked. Normality tests of the residuals are applied. ACF and Portmanteau BoxPierce test can be applied on the residuals from the estimated model to verify that the residuals are uncorrelated, which confirms that the estimated model captures most the information the series could provide.

It is possible that more than one model will be identified. In this case, the number of significant terms or parsimony, smallest corrected Akaike Information Criterion (AICc), and prediction variance are relied on to select the final model 12.

Details of the ARMA and SARIMA models as well as ITS analysis are given in Box et al. 12 and Cryer \& Chan 14.

The development of the study occurred as recommended by Resolution $n$. 196/96 of the Brazilian National Health Council. The project was approved by the Ethics Committee in Research of State University of Maringá (Legal Report 140/2009) and the Term of Free and In- formed Consent was not used because the data were secondary.

\section{Results}

From 2000 until 2011, 108,298 hospitalizations were registered in Paraná State according to the classification of ICD-10, codes A00-A09, for a population of 10,261,004 children under 5 years old. The average HRs varied from 118.09 to $65.09 / 10,000$ during the study period. The average and standard deviations for HRs according to the year and group age are presented in Table 1. The largest average reached was 250.36 in 2000 for children younger than 1 year old.

The average by year considering all age groups was 104.47 for 10,000 children. The absolute standard deviations before the VORH were smaller than after the VORH, e.g., 142.18 versus 74.59 for the children younger than 1 year old. On the other hand, as the averages were drastically reduced, the relative standard deviations should be observed by the variation coefficient (standard deviation divided by the average). Thus, it is possible to note that before the VORH, the variation ranged from $48 \%$ to $55 \%$, while after the VORH, the variation coefficients were almost the same, ranging from $45 \%$ to $50 \%$, representing the heterogeneity of the HRs.

Hospitalization rates (HRs) according to age, year, average, standard deviation (SD) and coefficient of variation (CV). Paraná State, Barzil, $2000-2011$.

\begin{tabular}{|c|c|c|c|c|c|c|c|c|c|c|c|}
\hline \multirow{2}{*}{ Year } & \multicolumn{2}{|c|}{$<1$ year } & \multicolumn{2}{|c|}{1 year } & \multicolumn{2}{|c|}{2 years } & \multicolumn{2}{|c|}{3 years } & \multicolumn{2}{|c|}{4 years } & \multirow[t]{2}{*}{ Average } \\
\hline & HR & SD & HR & SD & HR & SD & HR & SD & HR & SD & \\
\hline 2000 & 250.36 & 179.18 & 176.4 & 121.91 & 84.94 & 63.58 & 51.28 & 41.08 & 37.64 & 33.03 & 118.09 \\
\hline 2001 & 246.42 & 166.46 & 210.67 & 143.56 & 94.13 & 70.25 & 59.05 & 51.27 & 40.78 & 37.06 & 128.01 \\
\hline 2002 & 196.25 & 136.80 & 183.60 & 104.59 & 104.09 & 61.25 & 60.82 & 33.80 & 44.60 & 24.06 & 116.16 \\
\hline 2003 & 174.64 & 128.36 & 181.01 & 111.41 & 113.49 & 71.54 & 73.91 & 50.13 & 50.53 & 32.41 & 117.23 \\
\hline 2004 & 162.46 & 106.84 & 167.94 & 100.34 & 96.93 & 60.54 & 61.63 & 48.60 & 46.77 & 35.99 & 105.75 \\
\hline 2005 & 154.31 & 67.91 & 172.77 & 199.13 & 100.53 & 49.33 & 62.28 & 34.98 & 46.75 & 27.76 & 105.96 \\
\hline 2006 & 142.61 & 81.84 & 183.2 & 116.75 & 99.74 & 66.12 & 66.30 & 48.51 & 45.21 & 30.83 & 106.03 \\
\hline 2007 & 122.04 & 73.94 & 133.56 & 77.44 & 84.07 & 47.21 & 52.26 & 33.14 & 41.15 & 28.83 & 84.61 \\
\hline 2008 & 153.62 & 80.64 & 177.93 & 84.87 & 118.52 & 60.32 & 73.25 & 35.43 & 50.97 & 30.61 & 112.37 \\
\hline 2009 & 125.73 & 69.16 & 122.92 & 65.96 & 73.77 & 43.50 & 52.70 & 35.80 & 41.64 & 26.64 & 81.63 \\
\hline 2010 & 144.30 & 75.73 & 180.73 & 103.91 & 105.94 & 60.74 & 73.81 & 34.88 & 62.64 & 32.28 & 112.71 \\
\hline 2011 & 96.01 & 54.45 & 91.26 & 58.12 & 58.87 & 34.45 & 42.65 & 24.28 & 38.16 & 20.77 & 65.09 \\
\hline Average (2000-2005) & 255.86 & 142.18 & 241.50 & 116.42 & 133.19 & 64.37 & 83.41 & 46.00 & 59.81 & 33.05 & 154.75 \\
\hline $\mathrm{CV}$ & 0.56 & & 0.48 & & 0.48 & & 0.55 & & 0.55 & & \\
\hline Average (2007-2011) & 163.91 & 74.59 & 181.33 & 89.96 & 118.33 & 56.87 & 76.48 & 36.49 & 59.75 & 29.82 & 122.32 \\
\hline CV & 0.46 & & 0.48 & & 0.48 & & 0.48 & & 0.50 & & \\
\hline
\end{tabular}


The age group composed of children younger than 1 year old represented $30.64 \%$ of hospitalizations; the age group of 1-year-old children, $30.52 \%$; the 2 -year-old group, $17.95 \%$; the 3 -year-old group, $11.81 \%$; and the age group with the lowest rate of hospitalization was the 4-year-old group, with $9.07 \%$.

After verifying the time series stationarity for each one of the 144 time series (22 health regions and 5 age groups for each health region) by ACF and Dickey-Fuller test, one or more models were identified. For most of the time series at least 1 autoregressive parameter and 1 seasonal parameter of 12 months (annual) were indicated from ACF and PACF to be included in the model. The best model for each time series was chosen considering the statistically significant estimated parameters $(\mathrm{p}<0.05)$, the smallest predictive variance and smallest AIC. The validation of the model chosen was evaluated by residuals analysis. Using a Portmanteau test (Box-Pierce test), it was verified that all residuals did not present statistically significant correlation.

Once the models were estimated and validated, the adjusted models (gray line) were plotted in relation to the original series (black line) for each age group. In Figures 1 and 2, one can see the graphics for the younger than 1 year old and 1-year-old groups, respectively. The dashed line is the average level for the period before the vaccine (20002005).

In Figure 1, one can note that the adjusted model for most of the HR time series of children younger than 1 year old shows a decrease. However, for health region 18 , a clear increase can be noted. The quantification of the decreases or increases was evaluated by the estimated slope parameter. This parameter indicates the reduction by month per 10,000 children. This effect of reduction is better understood when projected at the end of the analyzed period (December 2011). The projected effects are presented in Table 2. When the slope estimated parameter was not statistically significant, the projected effect was represented by zero. For children younger than 1 year old, considering each regional division specifically, there were reductions in HRs in 11 regional divisions $(1,7,910,12,13,14,15,16$, 20 , and 22) with 12-32 reduced cases/month per 10,000 hospitalizations, 4 regional divisions (3, 15,19 , and 21) with no statistically significant decrease, and 1 regional division with a statistically significant increase of 6 cases/month/10,000. The average reduction by regional division in this age group was 11 cases/month/10,000 (Table 2). By analyzing the percentage reduction of the HRs in December 2011 in relation to the average level of cases before the vaccine, this age group presented an average reduction of $47 \%$ by regional division (Table 2).

For 1-year-old children, the adjusted model also shows a statistically significant decrease in the HRs for most regional divisions accompanying the original series (Figure 2). In the evaluation of the 1-year-old age group, 13 regional divisions presented reductions of 12 to 32 hospitalizations/month/10,000. Regional divisions 18 and 21 also did not have statistically significant decreases for this age group, and regional division 2, which had a slight decrease for children younger than 1 year, did not have a decrease in the HR for the one-year-old group. It was also verified that the average percentage reduction of HRs by regional division was $58 \%$ (Table 2 ).

In the time series for the age groups of 2and 3-year-old children, when the decrease occurred, it was less dramatic, with reductions of up to 19 cases/month/10,000 hospitalizations. Most regional divisions had no statistically significant reduction $(\mathrm{p}>0.05)$ (Table 2$)$. For these age groups, the average percentage reduction of HRs in December 2011 in relation to the average level before the vaccine was $21 \%$ and $7 \%$, respectively (Table 2). In the 4 -year-old age group, most regional divisions had no statistically significant reduction in $\mathrm{HR}$, and, in fact, slight increases were verified in 5 regional divisions.

When the average pre-vaccination level (65 cases/month $/ 10,000$ ) of the HRs by regional division is compared with the post-vaccination period in December 2011 (36 cases/month/10,000), an average decrease of 29 cases/month/10,000 is observed. The largest decrease was for regional division 13 (100 cases/month/10,000). On the other hand, regional divisions 18 and 21 had increases of 8 and 4 cases/month/10,000 hospitalizations after the introduction of the VORH, respectively.

\section{Discussion}

For the study period 2000 to 2011, hospitalization rates for acute diarrhea confirm the magnitude of diarrheal disease on the health of children less than 5 years of age and the importance of programs aimed at reducing these rates, such as the rotavirus vaccine.

Considering the descriptive analysis in Table 1, a higher HR was observed in the pre-vaccination period for children younger than 1 year old (256 on average) and a lower HR for the 4-year-old age group (60 on average). After VORH introduction, these average rates decreased to 96 and 38 in 2011, respectively. Even with this reduction, rates above these averages were encountered in national and 
Adjusted models for hospitalization rates (HRs) of children younger than one year old and the original series of HRs, codes A00-A09, according to the regional health. Paraná State, Brazil, 2000-2011.
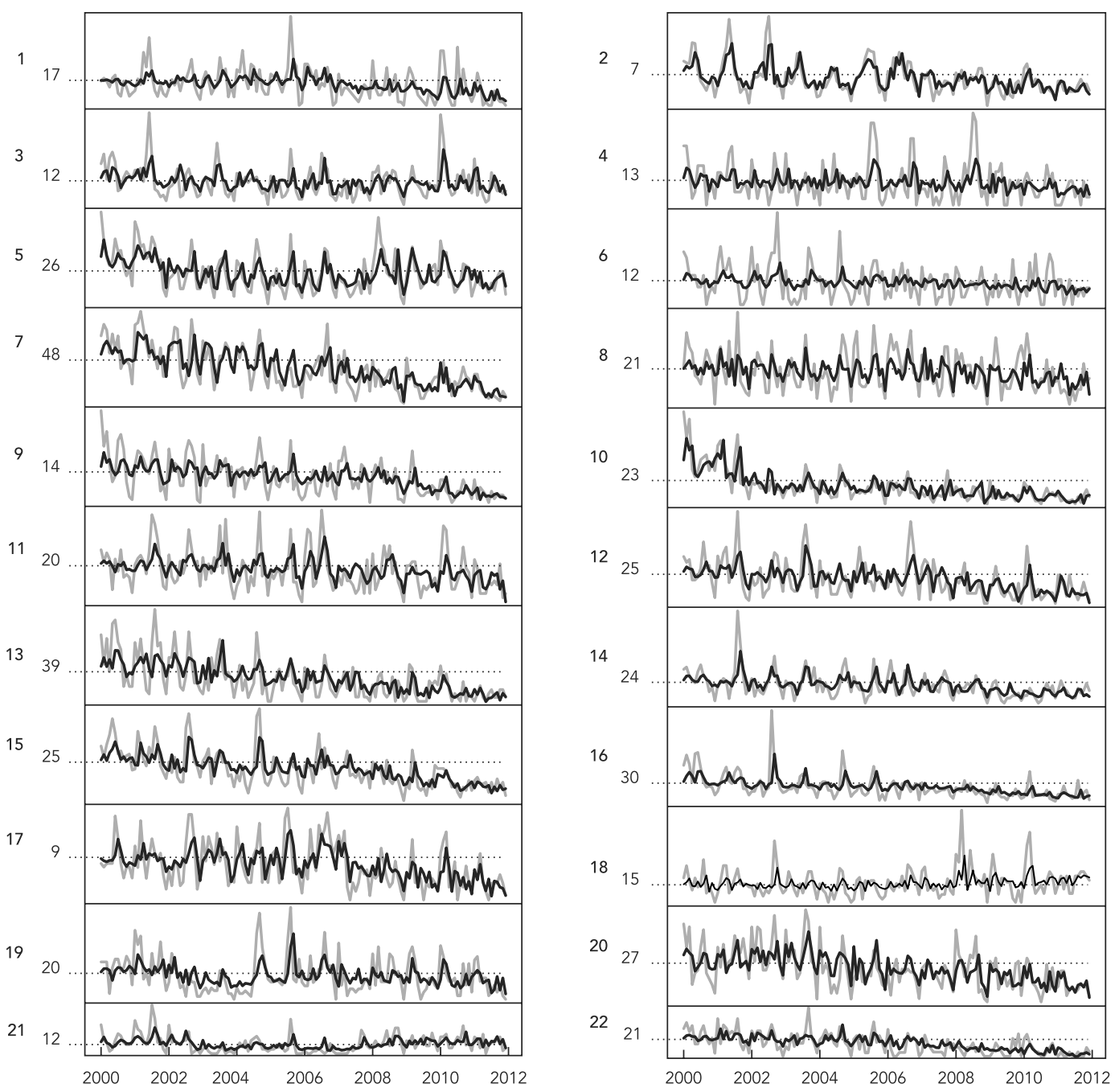

Black line: adjusted series;

Gray line: original series;

Dashed line: average level before 2006.

international literature. From a literature search of worldwide studies from 1986 to 2000 , the rate of hospitalizations due to acute diarrhea in children younger than 1 year old was found to be 71.25 cases per 10,000, and for children from 1 to 4 years old, the HR was 18.90 cases per 10,000 , highlighting the severity of diarrheal disease in small children until 2 years old, as most children in the later age range already have antibodies against rotavirus 14 .
If all age groups are considered, the average HR by month was 154.75 before the vaccine and 122.32/10,000 after. The HR was calculated by considering the entire population, although it is known that $24.5 \%$ of the population of the country has private health insurance and the hospitalization of these patients was not part of the database 15 . The great variation in HRs among the regional divisions from 2000 to 2011 is remarkable ranging from 35.30 to $344.55 / 10,000$ hospitaliza- 
Adjusted models for hospitalization rates (HRs) of children with one year old and original series of HRs, codes A00-A09, according to the regional health. Paraná State, Brazil, 2000-2011.


Black line: adjusted series

Gray line: original series;

Dashed line: average level before 2006.

tions for regional divisions 2 and 7, respectively. This variation in HRs is also evident observing the standard deviations in Table 1.

By ITS analysis, a higher reduction in the HR for children younger than 1 year old (21 cases/ month/10,000 on average by regional division) and a lower reduction in the HR for the age group of 4-year-old children (5 cases/month/10,000 on average by regional division) with decreases to 9 and 4 cases/month/10,000 in the end of 2011, re- spectively, was noted in the present study. Cases were reduced by an average of 29 cases/month by regional division.

Furthermore, by ITS analysis, it was observed that for children younger than or equal to 1 year old in all Paraná regional health divisions, 467 hospitalizations/month/10,000 were avoided, and for the other age groups, the reduction was small (93 cases/month), considering the projected effect in December 2011. In a study performed across 
Table 2

Reduction in hospitalization rates (HRs)/month/10,000 achieved in December 2011 and the reduction percentage in HRs December 2011, obtained from intervention analysis, according to regional health center. Paraná, Brazil, 2000-2011.

\begin{tabular}{|c|c|c|c|c|c|c|c|c|c|c|c|c|c|}
\hline \multirow[t]{2}{*}{ Regional heath center } & \multicolumn{2}{|c|}{$<1$ year } & \multicolumn{2}{|c|}{1 year } & \multicolumn{2}{|c|}{2 years } & \multicolumn{2}{|c|}{3 years } & \multicolumn{2}{|c|}{4 years } & \multirow{2}{*}{$\begin{array}{l}\text { Total } \\
\star \star \star\end{array}$} & \multicolumn{2}{|c|}{ Average } \\
\hline & $n$ * & $\% * \star$ & $\mathbf{n}$ & $\%$ & $\mathbf{n}$ & $\%$ & $\mathbf{n}$ & $\%$ & $\mathbf{n}$ & $\%$ & & Pre \# & Post \#\# \\
\hline 1 & -12 & -69 & -13 & -76 & -3 & -38 & 0 & 0 & 4 & 138 & -24 & 49 & 25 \\
\hline 2 & -3 & -42 & 0 & 0 & 0 & 0 & 1 & 59 & 1 & 82 & -1 & 18 & 17 \\
\hline 3 & 0 & 0 & -15 & -82 & -8 & -73 & -4 & -63 & 0 & 0 & -27 & 52 & 25 \\
\hline 4 & -5 & -39 & -8 & -59 & 0 & 0 & 0 & 0 & 0 & 0 & -13 & 40 & 27 \\
\hline 5 & 0 & 0 & -18 & -68 & -9 & -60 & -4 & -48 & 0 & 0 & -31 & 82 & 51 \\
\hline 6 & -5 & -40 & -7 & -53 & 0 & 0 & 0 & 0 & 2 & 77 & -10 & 40 & 30 \\
\hline 7 & -32 & -67 & -26 & -67 & 0 & 0 & -2 & -17 & 0 & 0 & -60 & 126 & 66 \\
\hline 8 & -8 & -39 & -14 & -60 & 0 & 0. & 0 & 0 & 0 & 0 & -26 & 73 & 47 \\
\hline 9 & -12 & -87 & -9 & -81 & 0 & 0 & 0 & 0 & 0 & 0 & -21 & 37 & 16 \\
\hline 10 & -19 & -84 & -13 & -72 & 0 & 0 & 0 & 0 & 0 & 0 & -32 & 59 & 27 \\
\hline 11 & -8 & -39 & -18 & -74 & 0 & 0 & 0 & 0 & 0 & 0 & -26 & 74 & 48 \\
\hline 12 & -16 & -65 & -13 & -58 & -5 & -40 & -5 & -52 & 0 & 0 & -39 & 75 & 36 \\
\hline 13 & -31 & -79 & -32 & -93 & -19 & -91 & -11 & -73 & -7 & -67 & -100 & 120 & 20 \\
\hline 14 & -14 & -59 & -9 & -41 & -4 & -35 & 0 & 0 & 0 & 0 & -27 & 71 & 44 \\
\hline 15 & -19 & -77 & -13 & -56 & 0 & 0 & 0 & 0 & 0 & 0 & -32 & 75 & 43 \\
\hline 16 & -23 & -77 & -19 & -67 & -5 & -37 & -3 & -35 & 0 & 0 & -50 & 86 & 36 \\
\hline 17 & -6 & -68 & -4 & -51 & 2 & 57 & 2 & 79 & 3 & 173 & -3 & 24 & 21 \\
\hline 18 & 6 & 41 & 0 & 0 & 0 & 0 & 0 & 0 & 2 & 39 & 8 & 56 & 64 \\
\hline 19 & 0 & 0 & -12 & -56 & -6 & -48 & 0 & 0. & 0 & 0 & -18 & 69 & 51 \\
\hline 20 & -14 & -53 & -22 & -74.9 & -6 & -40 & -3 & -31 & 0 & 0 & -45 & 88 & 43 \\
\hline 21 & 0 & 0 & 0 & 0 & 0 & 0 & 3 & 74 & 1 & 0 & 4 & 42 & 46 \\
\hline 22 & -20 & -94 & -21 & -100 & -7 & -57 & -33 & -44 & 0 & 0 & -51 & 67 & 16 \\
\hline Average cases reduction & -11 & -47 & -13 & -58 & -4 & -42 & -1 & -6 & 0 & 19 & -29 & - & - \\
\hline Average pre \# & 21 & - & 20 & - & 11 & - & 7 & - & 5 & - & - & 65 & - \\
\hline Average post \#\# & 9 & - & 8 & - & 7 & - & 5 & - & 4 & - & - & - & 36 \\
\hline
\end{tabular}

* Reduction in the rate of hospitalization/month achieved in December 2011;

** Percentage reduction (relative to the average level before the vaccine) in the rate of hospitalization in December 2011. The zero indicates that the estimated slope $(\omega)$ parameter was not statistically significant;

*** Total number of cases reduced in December 2011;

\# Average number of cases/month/10,000 pre-vaccine (2000-2005);

\#\# Average number of cases/month/10,000 after vaccination in December 2011.

all Brazilian regions, approximately 42,480 hospitalizations were avoided with the vaccine in all Brazilian territories between 2007 and 2009. However, for all Southern territories, where Paraná is located, there were 109 hospitalizations fewer than expected for children younger than 1 year old, and the sum of what was expected for until 4 years old had an increase of 149 cases, by the analysis of time series 7 .

It is important to highlight, as we can see in Figures 1 and 2, that the incidence of diarrhea has been decreasing for some regions since 2000, and the autoregressive characteristics of the SARIMA modeling in ITS analysis took this into account.
Furthermore, the adjustment underestimates the observed time series, as expected, due to the model structure. However, for some time series, the estimation was poor because the time series presented a random behavior, e.g., region 20 in Figure 2.

Although it was verified by ITS analysis that children younger than or equal to 1 year old were the most benefited with vaccination, other actions contribute to acute diarrhea prevention, such as incentivizing breastfeeding and better quality of primary attendance. These factors may be interfering in these values and may not be implemented homogeneously in all regional 
divisions, making necessary the improvement of more efficient strategies to support the municipalities and influence the management of regional issues to foment the continuous and growing search for efficiency with quality.

The variations in HRs due to acute diarrhea in regional health divisions, even after the introduction of VORH, can be noted by the standard deviations in Table 1. This fact suggests a subordination of the data, weakening the usefulness of hospitalization rates as an indicator of morbidity, as some regional divisions may not have appropriate data quality, resulting in under-reporting of diarrheal disease. The system of notification does not identify the individual or multiple hospitalizations due to the same problem, which leads to an overestimation of the health problem and prevents the evaluation of re-hospitalization and transfers 15 Although it could help in the evaluation of prevention measures for acute diarrhea, records completed during hospitalization for the treatment of infectious diarrhea exclude the identified etiology, not excluding case studies that detected factors that lead children younger than 5 years old to hospitalization.

This great variation can also indicate that rotavirus outbreaks still happen and reach the population of children younger than 1 year old who received only the first dose of the vaccine. In Australia, a retrospective case-control study determined that the efficiency of the vaccine to protect against hospitalization during rotavirus outbreaks in native children was $57.1 \%$ with 1 dose of the vaccine and $84.5 \%$ with 2 doses 16 .

Another factor that may be influencing the hospitalization rates is the rotavirus vaccination coverage in Paraná State. In the present study, the vaccination coverage in 2006 was $50.13 \%$; this may be due to the irregular provision of vaccine to the health units. This year was also one with the highest dropout rate, where $34.02 \%$ of the children who had the first dose did not complete the basic plan of 2 doses. It is important to observe that this vaccine has different characteristics of other vaccines that allow the vaccination regimen to be completed at any age in children. Vaccine coverage was $83.51 \%$ for $2007,85.81 \%$ for $2008,86.61 \%$ for $2009,91.66 \%$ for 2010 and $93.21 \%$ for 2011 ; these rates are lower than the $95 \%$ vaccine coverage recommended by the Brazilian Ministry of Health. However, these results are better when compared with the data for all of Brazil 17. Despite higher vaccination coverage rates than in other regions of the country 7 in 2008 and 2010, an increase in HRs was observed with an average increase of 112 cases and up to 84.61 for 2007, 2009, and 2011 (Table 1). During the six years of vaccination coverage, there was a large percentage of unimmunized children, which is a concern because it is not yet known what will be the behavior of the natural disease for children over 2 years of age who have not received the vaccine.

In countries with VORH included in their basic calendar, as in the USA, it was verified in 2007 that after a year of the vaccine's use, with $49 \%$ vaccination coverage for the first dose, that the hospitalization rate due to acute diarrhea decreased by $16 \%$, and in the following year, with slightly more than a third of the children completing the vaccine schedule of 3 doses (pentavalent vaccine), the reduction was by $45 \% 18$. In El Salvador, it was noted that children younger than 2 years old with 2 doses of the vaccine (monovalent vaccine) had a $76 \%$ reduction in HRs due to rotavirus and a $51 \%$ reduction with 1 dose. In these studies, even with lower than recommended vaccination coverage, a significant reduction in the hospitalizations due to acute diarrhea was found 19, which suggests that VORH has an indirect protective effect, noting that in these studies there was the identification of the agent that led to hospitalization.

The identification of the acute diarrheal agent is necessary to evaluate the efficiency of the vaccine through the years because in clinical trials, the vaccine used in Brazil demonstrated efficiency against gastroenteritis caused by rotavirus G1P[8], G2P[4], G3P[8], G4P[8] and G9P[8] 4,5. Before the introduction of the vaccine, type G1P[8] was the most prevalent. In 2006, a rotavirus outbreak in Northeast Brazil had 780 cases, of which $100 \%$ of the 15 patients who were hospitalized were found to be positive for G2[P4] 20. In São Paulo, it was identified that the predominant serotype was G2 21.

The evaluation of the effect of the vaccine is complex as the decrease of HRs was also observed before the introduction of the VORH and important variations in these rates were noted even after the introduction of the vaccine, as was the case in 2008 when there was an increase in HRs in this study and others for the entire country ${ }^{6,7}$. Further, Brazil has not identified the diarrheal agent that led to the hospitalization of these children. Additionally, great regional differences in HRs in Paraná state were observed with similar results in other studies that evaluated all the hospitalizations in the country by region. Thus, studies that consider only data from sentinel hospitals for the disease may not demonstrate the effect of VORH on hospitalization rates.

\section{Conclusion}

This study concluded that hospitalization rates due to acute diarrhea, following a national trend, is decreasing in almost all regional health divisions 
of Paraná State, as was observed from 2006 to 2011. Despite the discussed limitations related to the data, from the ITS analysis with Box-Jenkins methodology, the effect of the introduction of VORH on the HRs due to acute diarrhea could be estimated.

The reduction in HRs in some regional divisions may be related to general measures of diarrheal disease prevention, the hospitalization registers or better rates of vaccination coverage. It is still necessary to have a national network for systematic epidemiological vigilance with the identification of cases of rotavirus hospitalization, as this strategy would ease the monitoring of vaccine efficiency and the disease behavior with circulation of serotypes that are not integrated in the vaccine composition due to the large antigenic diversity responsible for the multiplicity of serotypes, which may make their control difficult.

With the introduction of the vaccine, children younger than or equal to 1 year old presented more significant decreases in HRs. It is important to remember that the highest HRs are in this age group, which highlights the disease severity in small children, making necessary the need to discuss the causes of acute diarrhea in this age group and develop strategies for its reduction. As it was observed that there was no decrease for 3 and 4-year-old children, continuous monitoring will indicate whether the disease incidence for these age groups will decrease.

The reduction of the HRs was effective, but the continuous monitoring for a reduction in cases of acute diarrhea cannot be discarded, as these cases may be related to other factors beyond the vaccine. The evaluation of other interventions such as sanitation, breastfeeding, nutrition, oral rehydration and access to health care are also important factors to be studied.

Finally, most of the time series analyzed presented an annual seasonal effect. This finding reinforces the importance of considering aggregating the estimation of SARIMA models and ITS analysis and indicates the necessity for more investigations related to the seasonal behavior, which may be associated with climate factors.

\section{Resumen}

El objetivo de este estudio es investigar el impacto de la vacuna contra el rotavirus en las tasas de hospitalización, relacionadas con diarrea aguda en niños menores de 5 años, después de que se introdujese la vacuna en 2006. Se trata de un estudio observacional, analítico descriptivo de las tasas de hospitalización acaecidas entre 2000 y 2011 en 22 centros regionales de salud del estado de Paraná, Brasil. El efecto de la vacuna se evaluó mediante la aplicación de la serie de tiempo SARIMA/ metodología de Box-Jenkins de análisis de intervención, lo que demuestra que los declives de las series son diferentes después de la introducción de la vacuna, con el fin de estimar la magnitud de estos efectos en los niños menores 5 años de edad, por grupos de edad para cada región. Se ha encontrado una reducción estadísticamente significativa de centro/mes en las tasas de hospitalización para niños menores de 1 año de edad y de 1 año de edad, con un promedio de $47 \%$ y 58\%, respectivamente, en diciembre de 2011.

Vacunas contra Rotavirus; Diarrea; Hospitalización; Evaluación de Servicios de Salud

\section{Contributors}

All authors participated on conception,design, acquisitio, analysis and interpretation of data; drafting and revising the article critically for important intellectual content and final approval of the version to be published.

\section{Acknowledgments}

Este estudo fez parte do projeto matricial Impacto da Vacina do Rotavírus nas Taxas de Internações Hospitalares nas Doenças Diarréicas Agudas do Paraná (Edital 014/2008 - Programa de Apoio a Pesquisa Básica Aplicada; Fundação Araucária). 


\section{References}

1. World Health Organization. Diarrhea: why children are still dying and what can be done. New York: United Nations Children's Fund; 2009.

2. Parashar UD, Hummelmen EG, Bresee JS, Miller MA, Glass RI. Global illness and deaths caused by rotavirus disease in chindren. Emerg Infect Dis 2003; 9:565-72.

3. Ministério da Saúde. Informe técnico sobre a doença diarreica por rotavírus: vigilância epidemiológica e prevenção pela vacina oral de rotavírus. Brasília: Ministério da Saúde; 2006.

4. Bernstein DI. RIX4414 (Rotarix): a live attenuated human rotavirus vaccine. J Pediatr (Rio J.) 2007; 83:193-5.

5. Araujo EC, Clemens SA, Oliveira CS, Justino MC, Rubio P, Gabbay YB, et al. Safety, immunogenicity, and protective efficacy of two doses of RIX4414 live attenuated human rotavirus vaccine in healthy Brazilian infants. J Pediatr (Rio J.) 2007; 83:217-24.

6. Lanzieri TM, Costa I, Shafi FA, Cunha MH, Ortega-Barria E, Linhares AC, et al Trends in hospitalizations from all-cause gastroenteritis in children younger than 5 years of age in Brazil before and after human rotavirus vaccine introduction, 1998-2007. Pediatr Infect Dis J 2010; 29:673-5.

7. Carmo GMI, Yen C, Cortes J, Siqueira AA, Oliveira WK, Cortes-Escalente JJ, et al. Decline in diarrhea mortality and admissions after routine childhood rotavirus immunization in Brazil: a time-series analysis. PLoS Med 2011; 8:e1001024.

8. Medronho RA, Bloch KV, Luiz RL, Werneck GL. Epidemiologia. Rio de Janeiro: Editora Atheneu; 2008.

9. Gilmour S, Degenhardt L, Hall W, Day C. Using intervention time series analyses to assess the effects of imperfectly identifiable natural events: a general method and example. BMC Med Res Methodol 2006, 6:16

10. Box GEP, Tiao GC. A change in level of a non-stationary time series. Biometrika 1965; 52:181-92.

11. Ramsay CR, Matowe L, Grilli R, Grimshaw JM, Thomas RE. Interrupted time series designs in health technology assessment: lessons from two systematic reviews of behavior change strategies. Int J Technol Assess Health Care 2003; 19:613-23.
12. Box GEP, Jenkins GM, Reinsell GC. Time series analysis: forecasting and control. $3^{\text {rd }}$ Ed. Englewood Cliffs: Prentice-Hall; 1994.

13. Cryer JD, Chan KS. Time series analysis: with applications in R. New York: Springer; 2008. (Springer Texts in Statistics).

14. Parashar UD, Gibson CJ, Bresee JS, Roger IG. Rotavirus and severe childhood diarrhea. Emerg Infect Dis 2006; 12:304-6.

15. Bittencourt SA, Camacho ALB, Leal MC. O Sistema de Informação Hospitalar e sua aplicação na saúde coletiva. Cad Saúde Pública 2006; 22:19-30.

16. Field EJ, Vally H, Grimwood K, Lambert SB. Pentavalent rotavirus vaccine and prevention of grastroenteris hospitalizations in Australia. Pediatrics 2010; 126: e506-12.

17. Departamento de Informática do SUS. Propostas preliminares. http://www2.datasus.gov.br/DATASUS/ index.php?area $=0701$ \&item $=1$ \&acao $=11$ (accessed on 06/Apr/2010).

18. Curns AT, Steiner CA, Barrett M, Hunter K, Wilson E, Parashar UD. Reduction in acute gastroenteritis hospitalizations among US children after introduction of rotavirus vaccine: analysis of hospital discharge data from 18 US states. J Infect Dis 2010; 201:1617-24.

19. Palma O, Cruz L, Ramos H, Baires A, Villatoro N, Pastor D, et al. Effectiveness of rotavirus vaccination against childhood diarrhoea in El Salvador: casecontrol study. BMJ 2010; 340:C2825.

20. Araujo TME, Dantas JM, Carvalho CEF, Costa MAO. Surto de diarreia por rotavírus no município de Bom Jesus (PI). Ciênc Saúde Coletiva 2010; 15 Suppl 1:1039-46.

21. Munford V, Gilio AE, Souza EC, Cardoso DM, Cardoso DDP, Borges AMT, et al. Rotavirus gastroenteritis in children in 4 regions in Brazil: a hospital-based surveillance study. J Infect Dis 2009; 200 Suppl 1:S106-13.

Submitted on $04 / \mathrm{Jul} / 2013$

Final version resubmitted on $04 / \mathrm{Feb} / 2014$

Approved on 18/Mar/2014 